\title{
An Edge Preserving Image Denoising Framework Based on Statistical Edge Detection and Bilateral Filter
}

\author{
Ebru AYDOĞAN DUMAN \\ PhD in Computer Engineer, Bucak-Burdur, Turkey \\ Geliş Tarihi (Received): 28.11.2021, Kabul Tarihi (Accepted): 23.12.2021 \\ $\square$ Sorumlu Yazar (Corresponding author*): eaydogan@gazi.edu.tr \\ (C) +905076384398
}

\begin{abstract}
The task of reducing noise from an image is known as image denoising. Although there are various methods and algorithms proposed in the literature, the methods still have limitations. The approaches generally either fail to reduce noise adequately or cause to be lost while effectively reducing noise. Conventional methods have poor performance when considering the success of preserving region boundaries and small structures. Conversely, modern techniques are more effective to smooth images without over smoothing edge details. To address these deficiencies and benefits, in this paper, we aim to develop a framework, which is capable of detecting whether a pixel is a part of edges or textures in an image so the framework can decide which filter should be used depending on region information. The Rank Order Test Method is used to detect image edges. In this way, we determine both which neighbors should be included to build a filter mask in the calculation for each pixel and which filter method should be implemented. We have compared the performance of Bilateral Filter-based methods. Experiments demonstrate that the proposed framework outperforms in terms of both PSNR, SSIM and visual perception for the noise with standard deviations 10, 30,50 . While the average PSNR value was 30.33 DB for the proposed model, the method with the closest result achieved an average score of $28.33 \mathrm{DB}$.
\end{abstract}

Keywords: Bilateral filter, image denoising, region growing segmentation, statistical test

Öz

\section{İstatistiksel Kenar Algılama ve Bilateral Filtreye Dayalı Kenar Korumalı Gürültü Giderme Yöntemi}

Bir görüntüdeki gürültüyü azaltma işlemi, gürültü giderme olarak adlandırılır. Literatürde önerilen çeşitli yöntemler ve algoritmalar olmasına rağmen, yöntemlerin hala sınırlamaları bulunmaktadır. Yaklaşımlar genellikle ya gürültüyü yeterince azaltmakta başarısız olur ya da gürültüyü etkili bir şekilde azaltırken görüntünün kaybolmasına neden olur. Bölge sınırlarını ve küçük yapıları korumanın başarısı göz önüne alındığında, geleneksel yöntemlerin performansı düşüktür. Tersine, modern teknikler, kenar ayrıntılarını aşırı yumuşatmadan görüntüleri düzeltmek için daha etkilidir. Bu eksiklikleri ve faydaları göz önünde bulundurarak, bu çalışmada, bir pikselin bir görüntüdeki kenarların mı yoksa dokuların bir parçası mı olduğunu tespit edebilen ve böylece çerçevenin bölge bilgisine bağlı olarak hangi filtrenin kullanılması gerektiğine karar verebilen bir çerçeve geliştirilmesi amaçlanmıştır. Sıralama Testi Yöntemi, görüntü kenarlarını tespit etmek için kullanılır. Bu sayede her piksel için yapılan hesaplamada filtre maskesi oluşturmak için hangi komşuların dâhil edilmesi gerektiği hem de hangi filtre yönteminin uygulanması gerektiği belirlenmiştir. Çalışmada Bilateral Filtre tabanlı yöntemlerin performanslarını karşılaştırılmıştır Deneyler, 10,30 ve 50 standart sapmalara sahip gürültüler için önerilen çerçevenin PSNR, SSIM ve görsel algı açısından daha iyi performans sağladığını göstermektedir. Ortalama PSNR değeri 30.33 DB iken, en yakın sonuca sahip olan yöntem 28.33 DB ortalama puan elde etmiştir.

Anahtar Kelimeler: Bilateral filtre, gürültü giderme, alan büyütmeli bölütleme, istatistiksel test 


\section{INTRODUCTION}

During the acquisition and transmission process, various types of noises frequently corrupt images. At the same time, image quality is very essential for highlevel operations such as image segmentation or object detection. For this reason, noise reduction is the fundamental and critical problem in various image processing applications (Hong et al., 2009; Shao et al., 2014). Filtering is generally a neighborhood process, in which the value of any selected pixel in the output image is decided by employing some algorithms to the values of the pixels in the neighborhood of the target pixel. Traditional linear filters reduce noises with corruptions in edge structure in an image. These filtering algorithms cause over smoothened and blurred images. In order to overcome these limitations, modern image denoising methods want to remove or reduce noise level while preserving the features of the image and region boundaries.

Convoluting the image with a mask that represents a low-pass filter is a simple approach to reduce noise. Mean Filter, Gaussian smoothing filter (Gonzalez, 2016), Wiener filter (Benesty et al., 2005; Hong et al., 2018) are a variety of linear translation-invariant (LTI) filtering (Jain and Tyagi, 2016). Mean filtering is a very simple method of smoothing images and very efficient to reduce noise in textures of an image. The type of filter is a sliding-window spatial filter that changes each pixel value with the average of all the pixel values in the kernel, which is generally selected as $3 \times 3$ or larger size of square. Gaussian smoothing filter is a good choice when noises are normally distributed which is also known as the Gaussian distribution. However, the main drawback of LTI filtering methods is that they cannot preserve area borders and information when smoothing an image. They tend to blur edges and other important information needed for high-level image processing operations. To handle these disadvantages of linear filtering, edge-preserving methods have been proposed in the literature. Partial differential equations (PDEs) based methods such as nonlinear anisotropic filtering (Gerig et al., 1992; Srivastava et al., 2015) and total variation (Selesnick et al., 2015) are very popular in a large variety of image denoising fields (Weickert, 1998). Edge-preserving performance is good with PDE-based approaches but they are generally slow because of the iterative process. Another popular method for noise reduction is non-local algorithms. Buades et al. (2005) have proposed a method based on a non-local averaging of all pixels. Wavelet is also used for edge-preserving image denoising. The pioneering study via wavelet based method was proposed by Donoho (1995). Wavelet-based methods generally depend upon the usage of wavelet thresholding and shrinkage function (Singh et al., 2017). Wavelet coefficients suggest that coefficients with a large absolute value carry signal information while coefficients with a small value are dominated by noise. Replacing coefficients with a small value (assumed noisy) by zero and an inverse wavelet transform is applied to reconstruct the image signals. Due to multiresolution structure and sparsity features, Waveletbased methods have given good performance and grown from the general strategy of wavelet coefficients shrinkage to the more sophisticated methods (Chen et al., 2005; Dengwen and Wengang, 2008; Shen et al., 2017). Starck et al. (2002) described approximate implementations of curvelet and ridgelet transform. The paper offers easy implementation and low computational complexity. Candes et al. (2006) proposed a fast curvelet transform in order to preserve edges and provide near-optimal sparse representation. Non-local means is another method for edge preserving smoothing. Routray et al. (2018) proposed WBFCT method that combined Curvelet Transform and weighted bilateral filter. In this way, separation of high frequency components is aimed to obtain geometric features during reduction process of noise. Buades et al. (2005) proposed the non-local means (NL-means), based on a non-local averaging of all pixels in the image. NLmeans methods give good performance but need high computational complexity because of using global search for pixels with similar intensity.

Bilateral Filter (BF), proposed by Tamossi and Manducci (1998), is one of the well-known edge-preserving methods in spatial filters. Moreover, recent studies have shown that a bilateral filter can increase the quality of edge-preserving image smoothing effectively (Chen et al., 2020). It is also used in other image processing areas except for denoising such as contrast enhancement, optical flow mapping, medical imaging (Ünver et al., 2019), tone mapping, contrast enhancement, tone mapping. BF is a nonlinear and noniterative method, which is a weighted average of the local information, where the weights are found out based on temporal and radiometric distances between the target pixel and its neighbors. However, Bilateral Filter cannot adjust the effects of noise removal and edge preservation. The parameters, which are usually defined according to experimental results and types of problem, may not be well suited for noise reduction and edge preservation for all parts in an image. This means that the range and domain parameters of the Bilateral Filter must be chosen suitable and adaptively. 
Out of several BF applications, one of these is bilateral filter decomposition, which involves constructing a high dynamic range image from a single low dynamic range image (Wang et al., 2007). Zhang and Allebach (2008) have proposed an adaptive Bilateral Filter (ABF) for noise removal and sharpness enhancement. $A B F$ is capable of noise reduction and the parameters of $A B F$ are chosen after training process. An entropybased adaptive bilateral filter has been proposed by Frosio et al. (2015). In the study, supervised learning procedure is used to estimate the relation between local image features and the local optimal parameters. Cho et al. (2014) have presented the bilateral texture filter, a new image decomposition technique. It is aimed to separate texture and structure correctly by using patch shifts that preserve meaningful information of images. The method needs more computational time than standard BF. Chaudhury and Rithwik (2015) have proposed a weighted bilateral filter in which a simple pre-processing step is added to adjust parameters to minimize mean-squared error (MSE). The filter is guaranteed to perform better than conventional $\mathrm{Bi}$ lateral Filter with almost no additional computational time.

In this paper, an edge detection-based image denoising framework is presented. Firstly modified robust rank order test (MRRO) (Lim, 2006; Duman and Erdem, 2018) is used for edge detection in a noisy image. In this way, all pixels are classified as edge pixels or texture pixels. According to the results of the edge detection process, Bilateral Filter is applied to edge pixels. Mean filter with the adaptive mask is applied for texture pixel. Adaptive masks are obtained by applying region-growing segmentation to target texture pixels. Adjacent pixels are tested whether they are in the same region or texture with a target pixel. Thus, the mean filter kernel is formed according to segmentation results. With the use of Structural Similarity Index Measurement (SSIM) and peak signal-to ration (PSNR), the experiments were carried out to assess the effectiveness of the proposed framework. In addition, the experimental results are compared to Bilateral filter-based methods and other state-of-art image denoising methods. Experimental results show that the proposed method outperforms other state-of-the-art image denoising methods in terms of both PSNR, SSIM values, and visual perception.

This article is organized as follows. In Section 2, the fundamentals of methods used in the framework are presented. These are Mean Filter, Bilateral Filter, Region Growing Segmentation Method and MRRO. Section 3 addresses the proposed framework; in Section
4, experimental results are shown and the effectiveness of the method is demonstrated. At last, Section 5 concludes the study.

\section{FUNDAMENTALS}

In this section, Mean Filter, Bilateral Filter, Region Growing Segmentation Method and Modified Robust Rank Order Test were presented.

\section{Mean Filter}

Mean filtering is a simple linear smoothing method for reducing noise in images. The average or weighted average of the target pixel and its neighbors is calculated with the Mean Filter. A mask is used for neighbor selection and their weights. Generally, the weights in the mask are uniform, but different weighted pixels can be chosen as shown in Figure 1 (b).

\begin{tabular}{|l|l|l|}
\hline 1 & 1 & 1 \\
\hline 1 & 1 & 1 \\
\hline 1 & 1 & 1 \\
\hline
\end{tabular}

(a)

\begin{tabular}{|l|l|l|}
\hline 1 & 2 & 1 \\
\hline 2 & 4 & 2 \\
\hline 1 & 2 & 1 \\
\hline
\end{tabular}

(b)
Figure 1. a) Mean with uniform weights, b) Mean with different weights

In the equation form, the filter is written as

$$
\mu[i, j]=\frac{1}{M} \sum_{k=i-1}^{i+1} \sum_{l=j-1}^{j+1} f[k, l]
$$

In the Equation 1, [i,j] represents any coordinate in an image, $M$ is the number of points in the average, and $[\mathrm{k}, \mathrm{l}]$ neighbors of the target pixel [i,j]. Mean Filtering Process computes the average value for [i,j] point according to selected $\mathrm{k}$ and $\mathrm{I}$ values.

The larger the mask, the more noise can be reduced, as more pixels will be involved in the calculation. On the other hand, larger masks cause edge blurring and result in an image with unclear edges. The biggest weakness of the method is its tendency to blur images because the values of edge pixels are considerably different from their neighbors. Therefore, it is rarely used 
in image denoising applications. However, if Mean Filter is used just in regions with big masks, it can produce better results.

\section{Bilateral Filter}

It is known that Gaussian filtering takes a weighted sum of the pixels in a local neighborhood, in which the weights change only according to distance from the target pixel.

Gaussian Convolution for an image is given by Equation 2.

$$
G C[I]_{p}=\sum_{q \in S} G \sigma(\|\mathrm{p}-\mathrm{q}\|) I_{q}
$$

Where $G_{q}(x)$ denotes the 2D Gaussian kernel is given by Equation 3.

$$
G_{\sigma}(x)=\frac{1}{2 \pi \sigma^{2}} \exp \left(-\frac{x^{2}}{2 \sigma^{2}}\right)
$$

The Gaussian $\sum_{q \in S} G \sigma(\|p-q\|)$ determines the pixel weight, where $\sigma$ is the neighborhood size parameter. The intensity of this effect is only determined by the distance between the pixels, not by their values. The method is nonlinear, local, and simple to smooth images while preserving edges efficiently. Bilateral Filter is a modified low-pass Gaussian Filter and is also known as a weighted average of pixels. The main distinction between Gaussian and Bilateral Filter is that the Bilateral Filter considers the weights depending on both their photometric similarity and geometrical closeness. The output of Bilateral Filter at pixel position $x$ is described mathematically as in Equation 4.

$$
B F[I]_{P}=\frac{1}{W_{P}} \sum_{q \in S} G \sigma_{S}(|| \mathrm{p}-\mathrm{q}||) G \sigma_{r}\left(\left|I_{p}-I_{q}\right|\right) I_{q}
$$

Where $\mathrm{W}_{\mathrm{P}}$ is the normalization factor that guarantees that the pixel weights add up to 1 .

The image's filtering level will be measured by parameters $\sigma_{s}$ and $\sigma_{r}$ for the image I. $G \sigma_{s}$ is a spatial Gaussian that reduces the effect of distant pixels in Equation 5. $G \sigma_{r}$ a range Gaussian that reduces the effect of pixels $\mathrm{q}$ with an intensity value different from $I_{p}$. By contrast to space, which relates to pixel location, the term range quantifies numbers associated with pixel values. When the range parameter is increased, the bilateral behaves like Gaussian blur, and when the spatial parameter is increased, the filter smooths larger features.

$$
w_{P}=\sum_{q \in S} G \sigma_{S}(|| \mathrm{p}-\mathrm{q}||) G \sigma_{r}\left(\left|I_{p}-I_{q}\right|\right)
$$

\section{Region Growing Segmentation}

Region growing is a simple region-based segmentation method that merges pixels or sub-regions based on satisfying a pre-defined similarity measure. The pixel grouping initiates with a set of seed marks in a way that the corresponding regions grow by joining each seed point and neighboring pixels that have similar features such as gray level, texture, shape, or color.

The first step is choosing seed pixels in an image. It is important that there should be at least one seed for each different region. The growing formula determines the homogeneity between a seed and its adjacent based on similarity measure. The threshold should be adequate to distinguish neighboring pixels in an inhomogeneous domain (Verma et al., 2011).

For the grow formula, a similarity measure between the seeds and the neighboring pixels is used. Every neighbor is checked for distance according to the seed point. If the distance is less than the selected threshold value then it is decided both pixels belong to the same region. The following pseudo codes provide further information on how standard region growing segmentation is implemented in the study. 
An Edge Preserving Image Denoising Framework Based on Statistical Edge Detection and Bilateral Filter

Algorithm 1. Pseudocode of general region growing segmentation method

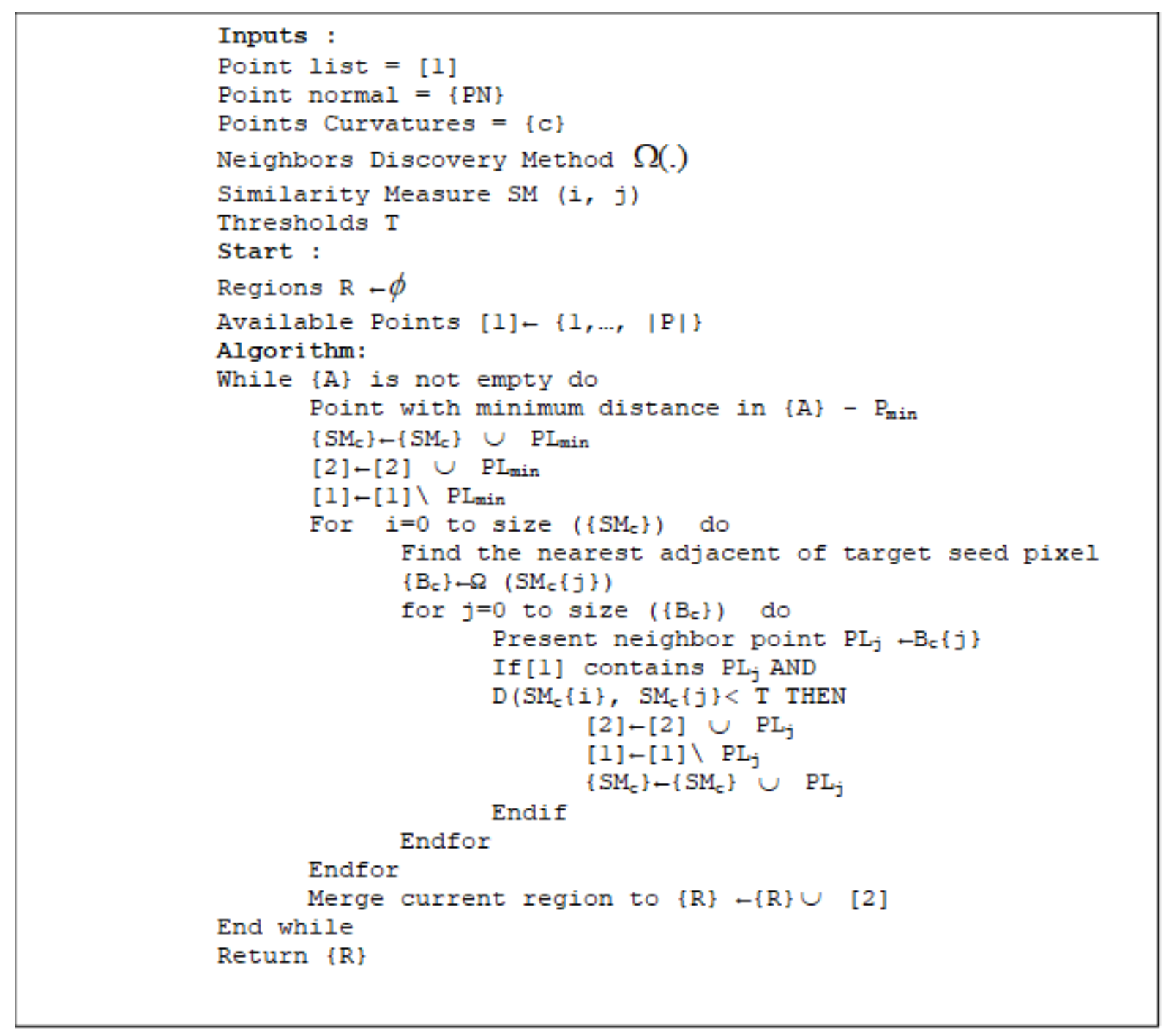

\section{Modified Rank Order Test-Based Edge Detector}

Conventional edge detection methods are very sensitive to noise in the image and they often need noise reduction pre-process. Statistical tests such as T-test, Wilcoxon Test and Rank Order have been used to detect edges in corrupted images. Rank order test-based edge detector has been proposed to detect edges in corrupted images with noise by Lim (Lim, 2006; Hoon $\mathrm{Lim}, 2006)$. The statistical algorithm RRO offers to detect local changes between neighboring pixels in noisy images via using the edge-height model. In this paper, a Rank Order Test-based edge detector (Lim, 2006;
Duman and Erdem, 2018) is used to detect edges of images.

For each pixel, which is needed to evaluate, $\mathrm{rx} r$ size sub-image is chosen. $r$ must be odd and set suitably according to the image and its size. In this work, $r$ is chosen as 5, as shown in Hata! Başvuru kaynağı bulunamadı.. Two different regions are considered a set of $\mathrm{N}=\mathrm{m}+\mathrm{n}$, excluding the target pixel. The groups are $\mathrm{X}=\left(\mathrm{X}_{1}, \mathrm{X}_{2}, \ldots \mathrm{X}_{\mathrm{M}}\right)$ and $Y=\left(\mathrm{Y}_{1}, \mathrm{Y}_{2}, \ldots \mathrm{Y}_{\mathrm{N}}\right)$, the model has been constructed as in Equation 6 . 


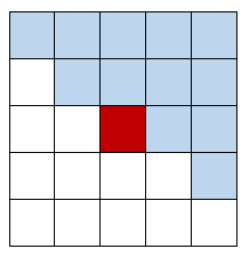

(a)

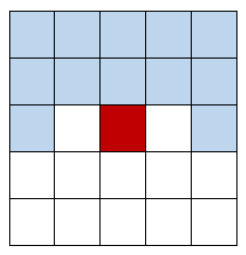

(e)

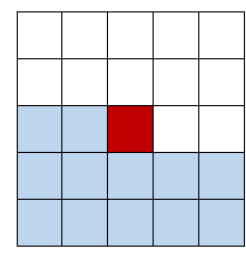

(b)

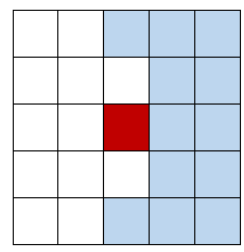

(f)

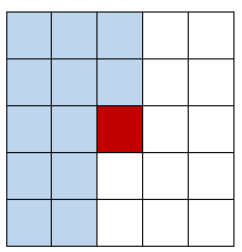

(c)

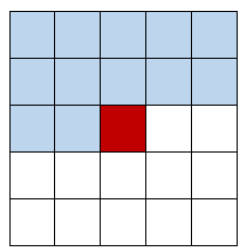

(g)

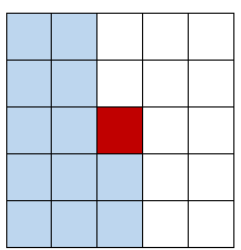

(d)

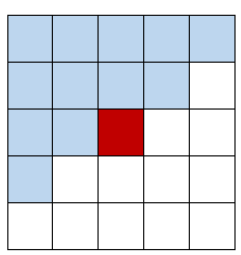

(h)

Figure 2. Possible eight distinct edge scenarios where a blue pixel denotes $\mathrm{Y}$ region and a white pixel denotes $\mathrm{X}$ region in the mask

$$
A_{i}=\left\{\begin{array}{cc}
X_{i}, & X_{i} \in X \\
Y_{j}, & Y_{i} \in Y
\end{array}\right\}
$$

Null hypothesis and alternative hypothesis are set as Equation 7 and Equation 8 respectively.

$$
\begin{aligned}
& H_{0}: x \geq y \\
& H_{1}: x<y
\end{aligned}
$$

To evaluate $\mathrm{H}_{0}$ against $\mathrm{H}_{1},\left\{\mathrm{~A}_{\mathrm{i}}\right\}$ is acquired as follows: For each $X_{i}, \in X$ the sum of difference of lower- valued pixels $Y_{i}$ 's in $Y$ are calculated. Obtained number represents $X_{i}$ and is denoted by $U\left(Y, X_{i}\right)$. Then average of the $\mathrm{U}\left(\mathrm{Y}, \mathrm{X}_{\mathrm{i}}\right)$ is calculated by $\mathrm{U}(\mathrm{Y}, \mathrm{X})=\sum_{\mathrm{i}=1}^{\mathrm{m}} \mathrm{U}\left(\mathrm{Y}, \mathrm{X}_{\mathrm{i}}\right) / 12$. This calculation is also done for $Y$ pixels $Y_{i}, Y_{i}, \in Y$. $\mathrm{U}\left(\mathrm{X}, \mathrm{Y}_{\mathrm{i}}\right)$ is calculated with the sum of the difference of lower-valued pixels $X_{i}$ ' $s$ in $X$. Then an average of the $\mathrm{U}\left(\mathrm{Y}, \mathrm{X}_{\mathrm{i}}\right)$ is calculated by $\mathrm{U}(\mathrm{X}, \mathrm{Y})=\sum_{\mathrm{i}=1}^{\mathrm{m}} \mathrm{U}\left(\mathrm{X}, \mathrm{Y}_{\mathrm{i}}\right) / 12$. Next, the homogeneity index is established as in Equation 9 and Equation 10.

$$
\begin{aligned}
V_{X} & =\sum_{i=1}^{m}\left[U\left(Y, X_{\mathrm{I}}\right)-U(Y, X)\right]^{2} \\
V_{Y} & =\sum_{i=1}^{m}\left[U\left(X, Y_{\mathrm{i}}\right)-U(X, Y)\right]^{2}
\end{aligned}
$$

After obtaining test parameters and homogeneity index, the test statistic has been built as in Equation 11 and Equation 12.

$$
\begin{gathered}
U=\left|\frac{m \cdot U(Y, X)-n \cdot U(X, Y)}{2 \sqrt{V_{X}+V_{Y}+U(Y, X)} \cdot U(X, Y)}\right| \\
U_{\text {selected }}=\max \left(U_{i}\right) \quad \mathrm{i}<=0
\end{gathered}
$$

For each of the eight edge cases, the $U$ value is computed eight times. $\mathrm{H}_{0}$ rejected and the pixel is assigned as an edge pixel if any $U$ value exceeds the threshold $\mathrm{u}_{\alpha}$.

\section{THE PROPOSED MODEL}

The general scheme of the proposed framework is shown in Figure 2. The framework is comprised of edge detection and filtering process according to results of the edge detection phase. The edge detection stage decides whether a target pixel belongs to a region or an edge. If the target pixel is decided to be in a region then the adaptive mask is formed via region growing segmentation. Therefore, similar pixels are collected in the form to apply the mean filter. If the target pixel is decided to belong to an edge in the image then Bilateral Filter is applied with suitable parameters for edge preservation. 


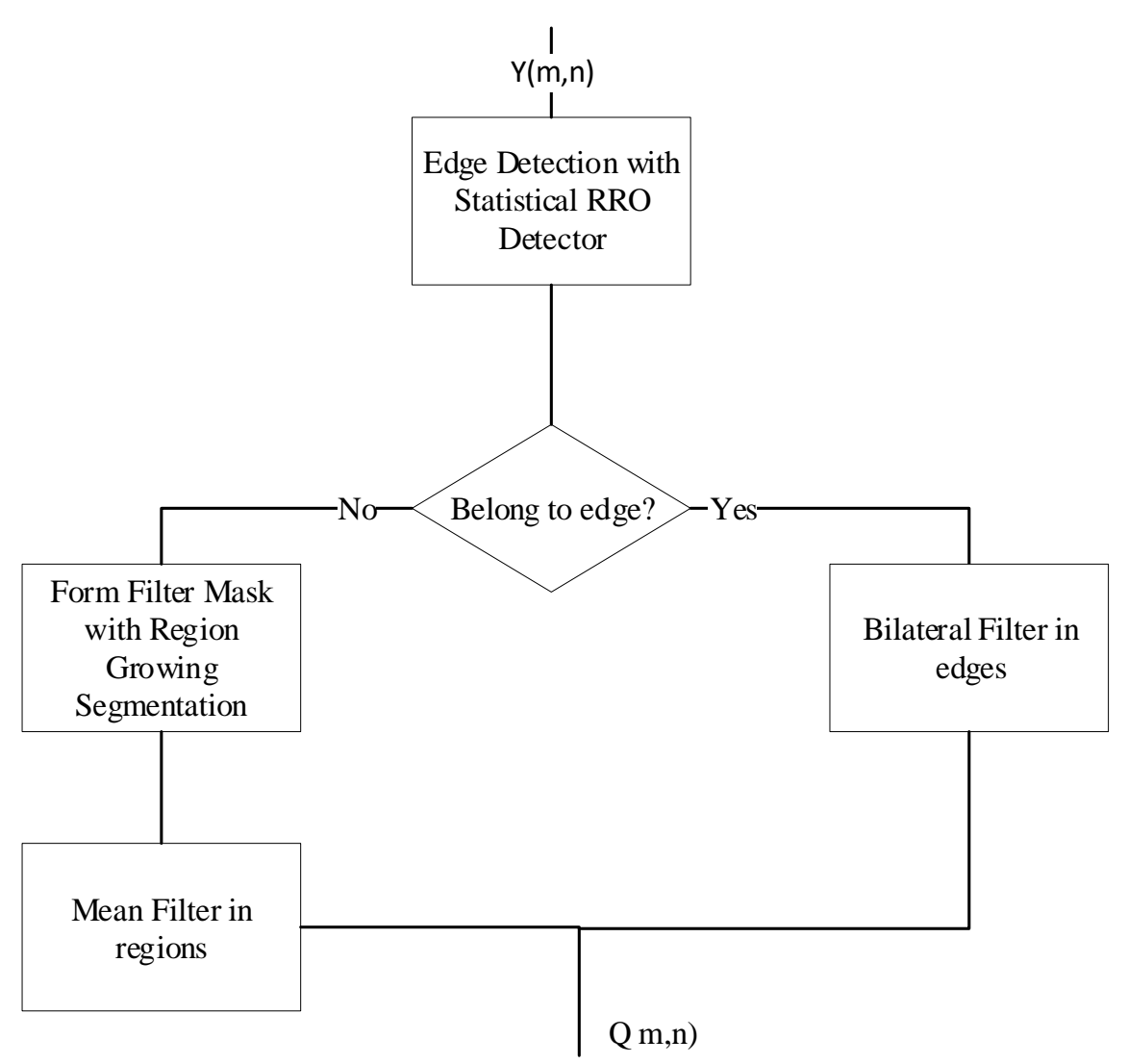

Figure 2. General scheme of the proposed framework

In this paper, a rank order-based statistical test is applied to an image to detect edges. For the noise with standard deviations $10,30,50$, the threshold $u \propto$ is set to $3.0,3.7,3.8$ respectively. After the edge detection process, predicted edges are obtained. An example is shown in Figure 4.

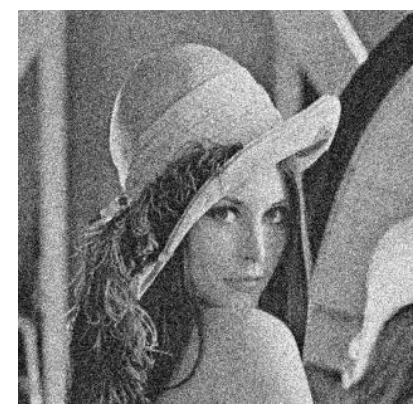

a

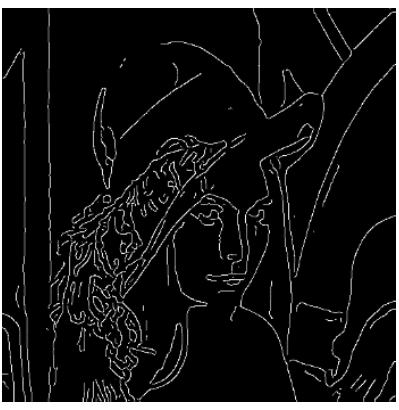

b
Figure 3. a. Noisy image, b. Obtained edges by Robust Rank Order Edge Detector

After obtained edges, Bilateral Filter is applied to obtained edges. In our problem, Region Growing Segmentation does not intent to segment the whole image.
Each pixel is chosen as a seed then it is checked whether it is in the regions or the boundaries. If it is in a region it is labeled as a region then only available neighbors selected using a $7 \times 7$ mask are tested based on similarity measure (Duman and Erdem, 2017). The concepts are illustrated in Figure 4.
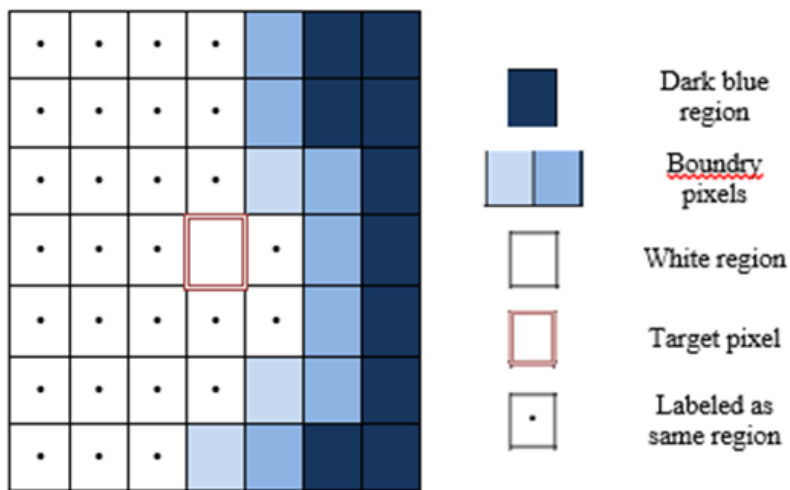

Figure 4. The schematic graph shows two different regions and the boundary between them. White pixels are joined to the region according to the target white pixel 
Euclidean Distance is used for similarity measures in the region growing segmentation. Euclidean distances are calculated for RGB values of an input pixel to its neighbors. Pixels include intensive noise so relying on pixel values might give wrong estimations. To obtain precise results, a pixel is represented by the average of its 8 adjacent and itself. Euclidean Distance is calculated as

$$
d(i, j)=\sqrt{\left(G_{i}-G_{j}\right)^{2}}
$$

In Equation 13, (i,j) is any two coordinates in a color image. $G$ indicates the average of 8 adjacent and its grayscale color value. To decide if the pixels are in the same region, the threshold is applied to their distance. In this work, two thresholds are used according to noise types. If Euclidean distance is less than 40 for an image corrupted by Gaussian noise, it is decided that both pixels are in the same region. After the region growing segmentation process, we will have a suitable mask for the target pixel. At last, Mean Filter is applied according to the formed mask.

\section{EXPERIMENTAL RESULTS}

In this section, our experimental results of Bilateral Filter based methods are presented to validate the performance of the proposed method. The proposed method was implemented using $\mathrm{C \#}$ on Visual Studio and experiments were conducted on Matlab R2017a to obtain PSNR and SSIM results. Barbara, Lena, Cameraman, and House, which have a dimension of $512 \times 512$, were used to evaluate the Bilateral Filter approaches. The tests were conducted on Barbara, Lena, Cameraman and House noisy types, which were polluted with additive white Gaussian noise. A quantitative comparison is performed between the performance of the proposed framework and the state-ofthe-art image denoising methods based on Bilateral Filter. These methods are Conventional BF, WBF, $\mathrm{WBF}+\mathrm{Wavelet}$, and ABF. For assessing the similarity between the filtered image and the original noise-free image in terms of noise reduction and edge protection, notable quality metrics were used. Peak Signal-toNoise Ratio (PSNR) (Huynh-Thu and Ghanbari, 2008) and Structural Similarity (SSIM) (Wang et al., 2004) were used to evaluate the noise reduction performance of Bilateral-based denoising algorithms.

\section{Performance Measures}

Peak signal-to-noise ratio (PSNR), which calculates the peak signal-to-noise ratio between images, was used for quality measurement between the original and filtered images. The mathematical representation of the PSNR is given by Equation 14 .

$$
P S N R=10 \log _{10} \frac{255^{2}}{M S E}
$$

Where the Mean Squared Error, abbreviated as MSE is given by Equation 15 .

$$
M S E=\frac{\sum_{i=1}^{N} \sum_{j=1}^{M}\left(x_{i, j}-\widehat{x}_{\hat{\imath}, j}\right)^{2}}{N x M}
$$

Where $x_{i, j}$ is the original image and $\hat{x}_{i, j}$ is the filtered image. $\mathrm{M}$ and $\mathrm{N}$ are the dimensions of the images. PSNR is a satisfying performance metric due to its easy calculation. However, it is not exactly the response of the human visual system (HVS), which can give a better reflection of the structural similarity between original image and filtered image. Structural similarity index (SSIM) is a metric conceived to simulate the response of HVS. SSIM results are in the range of -1 to 1 where a higher score means that two images are more similar. When calculating SSIM between two images, two patches are taken from the same coordinates of images $X$ and $Y$, and SSIM is calculated as follows

$$
\begin{aligned}
& \operatorname{SSIM}=\left(x_{P}, y_{p}\right) \\
& =\frac{\left(2 \mu_{x_{p}} \mu_{y_{p}}+C_{1}\right)\left(2 \sigma_{x_{p} y_{p}}+C_{2}\right)}{\left(\mu_{x_{p}}^{2}+\mu_{y_{p}}^{2}+C_{1}\right)\left(\sigma_{x_{p}}^{2}+\sigma_{y_{p}}^{2}+C_{2}\right)}
\end{aligned}
$$

In Equation 16, $x_{p}$ and $y_{p}$ is used for patches, $\sigma_{x_{p}}$ is the standard deviation, $\sigma_{\mathrm{x}_{\mathrm{p}} \mathrm{p}}$ is the standard covariance, and $\mathrm{C}_{1}-\mathrm{C}_{2}$ are the predefined constants.

\section{Performance Results}

The proposed framework was compared Bilateral Filter based methods in order to assess the denoising effectiveness. Figure 5 indicates the visual comparison results of Barbara image with 30 noise variance for Conventional BF, WBF, WBF + Wavelet, $A B F$, and Proposed Framework. Filtered images are obtained using Conventional BF, WBF, WBF + Wavelet, ABF and Proposed Framework with PSNR values of $20.05 \mathrm{~dB}, 24.98$ $\mathrm{dB}, 25.17 \mathrm{~dB}, 25.28 \mathrm{~dB}, 27.17 \mathrm{~dB}$; respectively. 
Figure 6 indicates the visual comparison results of Lena image with 30 noise variance for Conventional BF, WBF, WBF + Wavelet, ABF, and Proposed Framework. Filtered images are obtained using Conventional
BF, WBF, WBF + Wavelet, ABF and Proposed Framework with PSNR values of $20.89 \mathrm{~dB}, 29.78 \mathrm{~dB}, 29.54$ $\mathrm{dB}, 29.81 \mathrm{~dB}, 30.97 \mathrm{~dB}$; respectively.

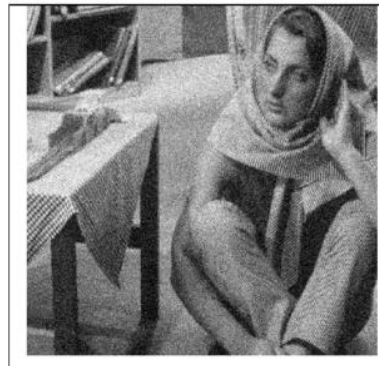

a

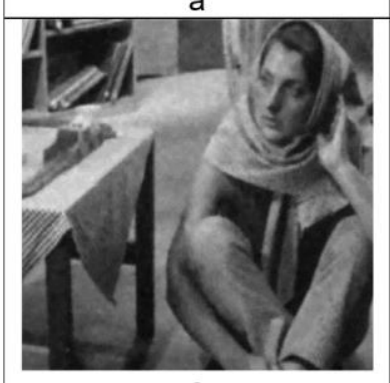

e

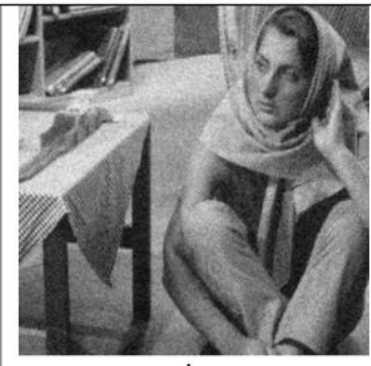

b

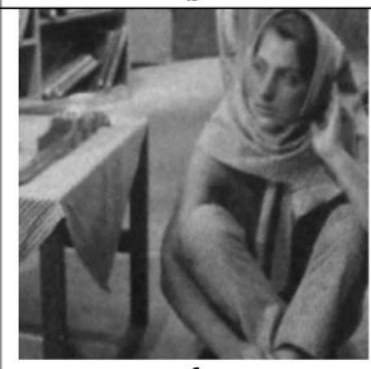

f

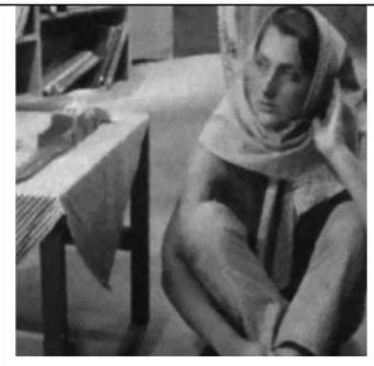

C

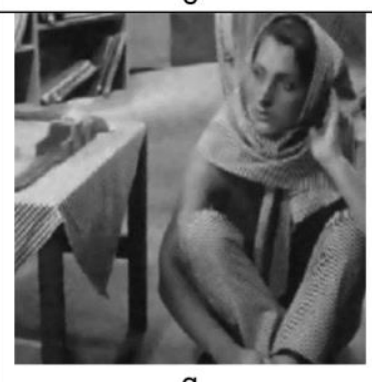

$\mathrm{g}$

Figure 5. The visual Comparison results of Barbara with $\sigma=30$ a. Noisy Image of Barbara, b. Conventional BF, c. WBF, d. WBF+wavelet, e. ABF, f. Proposed framework

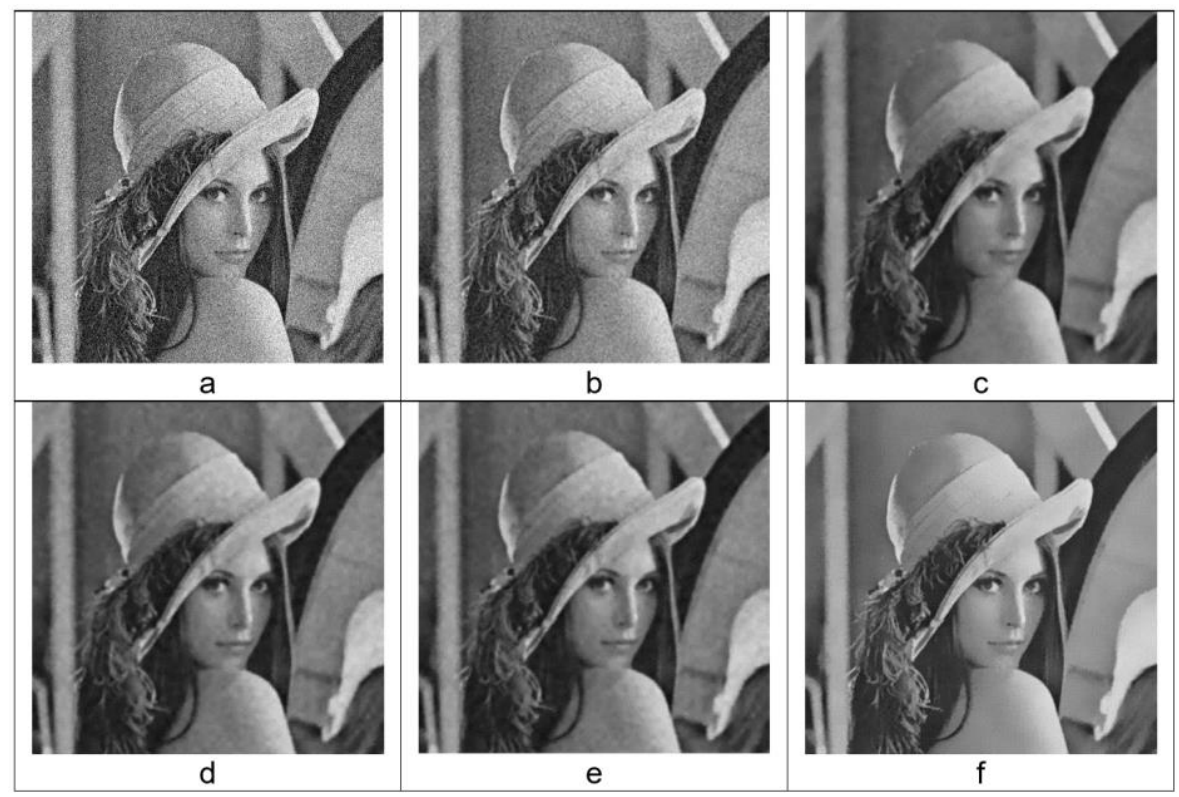

Figure 6. Denoising outputs of Lena with $\sigma=30$ a. Noisy Image of Lena, b. Conventional BF, c. WBF, d. WBF+wavelet, e) ABF, f) Proposed framework

Figure 8 indicates the denoising outputs of Conventional BF, WBF, WBF + Wavelet, ABF, and Proposed Framework for Cameraman image with 30 noise variance. Filtered images are obtained using Conventional
$\mathrm{BF}, \mathrm{WBF}, \mathrm{WBF}+\mathrm{Wavelet}, \mathrm{ABF}$, and Proposed Framework with PSNR values of $20.88 \mathrm{~dB}, 26.60 \mathrm{~dB}, 26.64$ $\mathrm{dB}, 26.76 \mathrm{~dB}, 29.55 \mathrm{~dB}$; respectively. 
Figure 8 indicates the denoising outputs of Conventional BF, WBF, WBF + Wavelet, ABF and Proposed Framework for House image with 30 noise variance. Filtered images are obtained using Conventional BF,
WBF, WBF + Wavelet, ABF, and Proposed Framework with PSNR values of $20.76 \mathrm{~dB}, 29.84 \mathrm{~dB}, 29.38 \mathrm{~dB}$, $29.88 \mathrm{~dB}, 31.45 \mathrm{~dB}$; respectively.

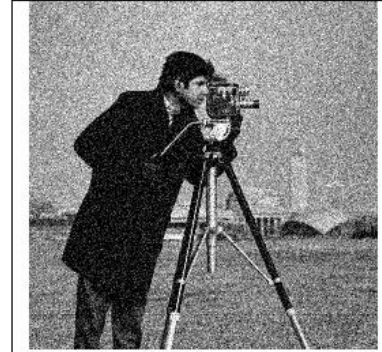

a

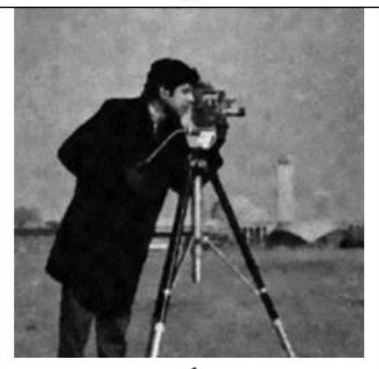

d

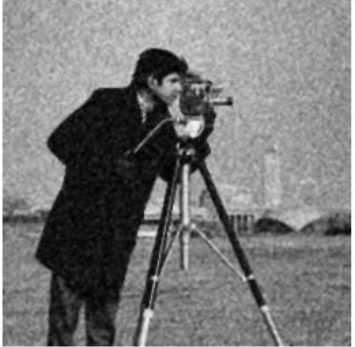

$\mathrm{b}$

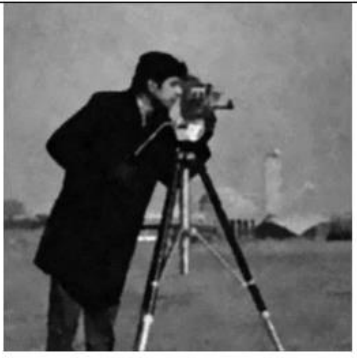

$\mathrm{e}$

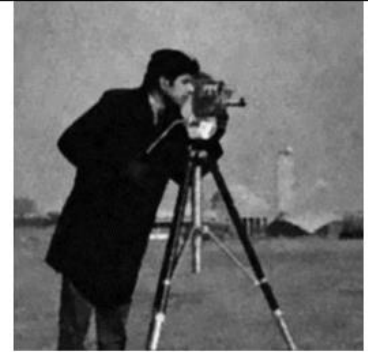

c

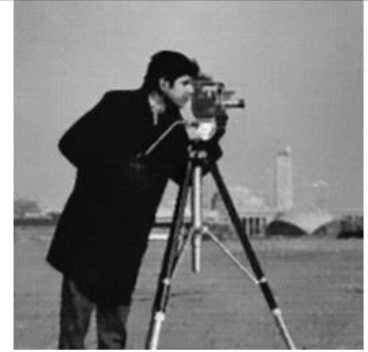

$\mathrm{f}$

Figure 7. Denoising outputs of Cameraman with $\sigma=30$ a. Noisy Image of Cameraman, b. Conventional BF, c. WBF, d. WBF+wavelet, e.ABF, f. Proposed framework

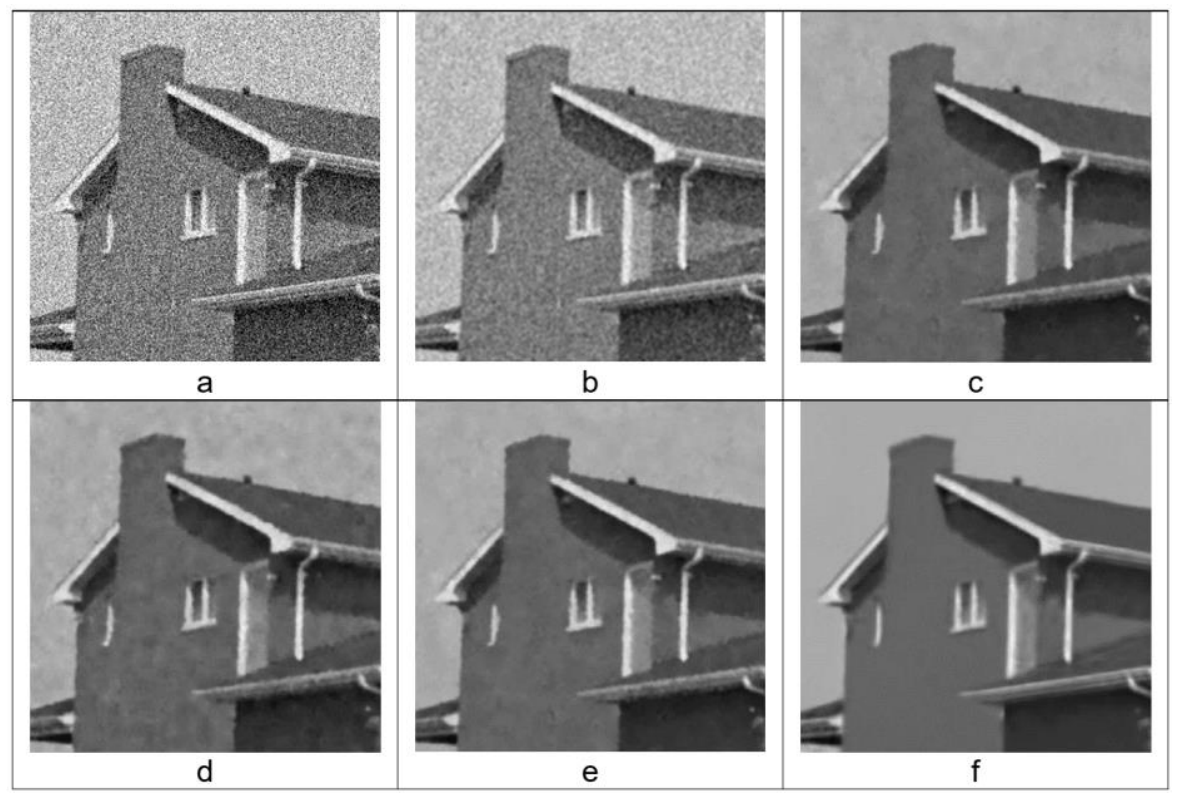

Figure 8. Denoising outputs of House with $\sigma=30$ a. Noisy Image of House, b. Conventional BF, c. WBF, d. WBF+wavelet, e. ABF, f. Proposed framework

Quantitative comparisons of Conventional BF, ABF, WBF, WBF + Wavelet and Proposed Framework are shown in Table 1 and Table 2 for PSNR and SSIM metrics, respectively. 
An Edge Preserving Image Denoising Framework Based on Statistical Edge Detection and Bilateral Filter

Table 1. Performance evaluation of Conventional BF, ABF, WBF, WBF + Wavelet, and Proposed Framework at noise variance $\sigma=10,30,50$ for PSNR

\begin{tabular}{|c|c|c|c|c|c|c|c|}
\hline Test Image & $\begin{array}{c}\text { Noise Vari- } \\
\text { ance }\end{array}$ & Noisy Image & $\begin{array}{c}\text { Conventional } \\
\text { BF }\end{array}$ & WBF & $\begin{array}{c}\text { WBF }+ \\
\text { Wavelet }\end{array}$ & ABF & $\begin{array}{c}\text { Proposed } \\
\text { Framework }\end{array}$ \\
\hline \multirow{3}{*}{ Barbara } & 10 & 27.89 & 30.44 & 30.29 & 30.56 & 30.54 & $\mathbf{3 1 . 0 4}$ \\
\cline { 2 - 9 } & 30 & 18.24 & 20.05 & 24.98 & 25.17 & 25.28 & $\mathbf{2 7 . 1 7}$ \\
\cline { 2 - 9 } & 50 & 14.10 & 15.28 & 22.84 & 22.88 & 22.96 & $\mathbf{2 4 . 6 4}$ \\
\hline \multirow{3}{*}{ Lena } & 10 & 28.05 & 32.49 & 32.91 & 33.80 & 32.79 & $\mathbf{3 5 . 1 2}$ \\
\cline { 2 - 9 } & 30 & 18.47 & 20.89 & 29.78 & 29.54 & 29.81 & $\mathbf{3 0 . 1 7}$ \\
\cline { 2 - 9 } & 50 & 14.08 & 15.10 & 26.12 & 26.01 & 26.05 & $\mathbf{2 8 . 0 8}$ \\
\cline { 2 - 9 } & 10 & 28.06 & 32.15 & 32.18 & 32.36 & 32.15 & $\mathbf{3 4 . 8 8}$ \\
\cline { 2 - 9 } & 30 & 18.48 & 20.88 & 26.60 & 26.64 & 26.76 & $\mathbf{2 9 . 5 5}$ \\
\hline \multirow{3}{*}{ House } & 10 & 14.11 & 15.04 & 23.57 & 23.75 & 24.12 & $\mathbf{2 5 . 7 5}$ \\
\cline { 2 - 9 } & 30 & 18.49 & 20.76 & 29.84 & 29.38 & 29.88 & $\mathbf{3 1 . 4 5}$ \\
\cline { 2 - 9 } & 50 & 14.10 & 16.41 & 26.18 & 25.92 & 26.14 & $\mathbf{2 7 . 8 5}$ \\
\hline
\end{tabular}

Table 2. Performance evaluation of Conventional BF, ABF, WBF, WBF + Wavelet, and Proposed Framework at noise variance $\sigma=10,30,50$ for SSIM

\begin{tabular}{|l|c|c|c|c|c|c|c|}
\hline Test Image & $\begin{array}{c}\text { Noise } \\
\text { Variance }\end{array}$ & Noisy Image & $\begin{array}{c}\text { Conventional } \\
\text { BF }\end{array}$ & WBF & $\begin{array}{c}\text { WBF+ Wave- } \\
\text { let }\end{array}$ & ABF & $\begin{array}{c}\text { Proposed } \\
\text { Framework }\end{array}$ \\
\hline \multirow{4}{*}{ Barbara } & 10 & 0.905 & 0.947 & 0.953 & 0.957 & $\mathbf{0 . 9 6 2}$ & 0.960 \\
\cline { 2 - 8 } & 30 & 0.625 & 0.672 & 0.817 & 0.821 & 0.828 & $\mathbf{0 . 8 4 5}$ \\
\cline { 2 - 8 } & 50 & 0.457 & 0.483 & 0.705 & 0.706 & 0.711 & $\mathbf{0 . 7 6 8}$ \\
\hline \multirow{4}{*}{ Lena } & 10 & 0.871 & 0.948 & 0.942 & 0.953 & 0.953 & $\mathbf{0 . 9 5 8}$ \\
\cline { 2 - 8 } & 30 & 0.529 & 0.619 & 0.875 & 0.861 & 0.878 & $\mathbf{0 . 8 8 7}$ \\
\cline { 2 - 8 } & 50 & 0.351 & 0.382 & 0.722 & 0.716 & 0.718 & $\mathbf{0 . 7 8 0}$ \\
\hline \multirow{4}{*}{ House } & 10 & 0.628 & 0.886 & 0.889 & 0.891 & 0.886 & $\mathbf{0 . 9 2 7}$ \\
\cline { 2 - 8 } & 30 & 0.285 & 0.347 & 0.703 & 0.706 & 0.713 & $\mathbf{0 . 8 1 8}$ \\
\cline { 2 - 8 } & 50 & 0.173 & 0.185 & 0.586 & 0.585 & 0.603 & $\mathbf{0 . 7 4 3}$ \\
\cline { 2 - 8 } & 10 & 0.598 & 0.853 & 0.868 & 0.871 & 0.879 & $\mathbf{0 . 9 4 6}$ \\
\cline { 2 - 8 } & 30 & 0.229 & 0.302 & 0.793 & 0.788 & 0.801 & $\mathbf{0 . 8 3 6}$ \\
\cline { 2 - 8 } & 50 & 0.125 & 0.205 & 0.604 & 0.589 & 0.605 & $\mathbf{0 . 7 6 5}$ \\
\hline
\end{tabular}

To evaluate the denoising effectiveness in terms of PSNR and SSIM, the performance of Bilateral Filter based methods was compared. PSNR and SSIM are two measuring metrics that are widely applied in image quality comparison. A low PSNR is obtained when the noisy image is compared with the reference image. If the noise removal is successful, a high PSNR value is obtained in the image comparison with the reference image. SSIM results are in the range of -1 to 1 where a higher score means that two images are more similar A value of 1 indicates that the 2 given images are the same. Respectively, Table 1 and Table 2 illustrate PSNR and SSIM values on reducing noise with noise variance 10,30 and 50 . The proposed framework achieves a better PSNR and SSIM than the other Bilateral Filter based methods except for the image Barbara at noise variance 10 for SSIM metric.

\section{CONCLUSION}

A new edge-preserving image denoising method that employs rank order-based nonparametric test to detect edges and region growing segmentation-based mask building has been introduced. Both the quantitative and qualitative analysis of the performance results indicate that the proposed framework effectively suppresses White Gaussian noise while preserving image boundaries and their information. Experiments demonstrate that the proposed method outperforms when compared with results obtained from other state-ofthe-art denoising methods based on Bilateral Filter in terms of PSNR, SSIM and visual perception. For future development of the proposed method, the used threshold for the rank order-based statistical test can be adapted for different noise levels with a method that can evaluate whether an image is complex or plain. 


\section{REFERENCES}

Bargshady, G., Zhou, X., Deo, R.C., Soar, J., Whittaker, F., Wang, H. (2020). Enhanced deep learning algorithm development to detect pain intensity from facial expression images. Expert Systems with Applications, 149, 113305; DOI: https://doi.org/10.1016/j.eswa.2020.113305

Benesty, J., Chen, J., Huang, Y.A., Doclo, S. (2005). Study of the Wiener filter for noise reduction. In: Speech enhancement, 9-41, Springer, Berlin, Heidelberg.

Buades, A., Coll, B., Morel, J. M. (2005). A non-local algorithm for image denoising. In: 2005 IEEE Computer Society Conference on Computer Vision and Pattern Recognition (CVPR'05), 2:60-65.

Candes, E., Demanet, L., Donoho, D., Ying, L. (2006). Fast discrete curvelet transforms. Multiscale modeling \& simulation, 5(3): 861-899.

Chaudhury, K.N., Rithwik, K. (2015). Image denoising using optimally weighted bilateral filters: A sure and fast approach. In: 2015 IEEE International Conference on Image Processing (ICIP), 108-112.

Chen, B.H., Tseng, Y.S., Yin, J.L. (2020). Gaussian-adaptive bilateral filter. IEEE Signal Processing Letters, 27: 16701674.

Chen, G.Y., Bui, T.D., Krzyżak, A. (2005). Image denoising with neighbour dependency and customized wavelet and threshold. Pattern Recognition, 38(1): 115-124.

Cho, H., Lee, H., Kang, H., Lee, S. (2014). Bilateral texture filtering. ACM Transactions on Graphics (TOG), 33(4): 18.

Dengwen, Z., Wengang, C. (2008). Image denoising with an optimal threshold and neighbouring window. Pattern Recognition Letters, 29(11): 1694-1697.

Donoho, D.L. (1995). De-noising by soft-thresholding. IEEE transactions on information theory, 41(3): 613-627.

Duman, E., Erdem, O.A. (2017). A new image denoising method based on region growing segmentation. In: $201725^{\text {th }}$ Signal Processing and Communications Applications Conference (SIU), 1-4.

Duman, E., Erdem, O.A. (2018). A statistical edge detection framework for noisy images. In: $201826^{\text {th }}$ Signal Processing and Communications Applications Conference (SIU), $1-4$.

Frosio, I., Egiazarian, K., Pulli, K. (2015). Machine learning for adaptive bilateral filtering. In: Image Processing: Algorithms and Systems XIII (Vol. 9399, p. 939908). International Society for Optics and Photonics; DOI: https://doi.org/10.1117/12.2077733

Gerig, G., Kubler, O., Kikinis, R., Jolesz, F.A. (1992). Nonlinear anisotropic filtering of MRI data. IEEE Transactions on Image Processing, 11(2): 221-232.

Gonzalez, R.C. (2016). Digital image processing. In: Prentice hall.

Hong, C., Yu, J., Zhang, J., Jin, X., Lee, K.H. (2018). Multimodal face-pose estimation with multitask manifold deep learning. IEEE Transactions on Industrial Informatics, 15(7): 3952-3961.
Hong, J.H., Cho, S.B., Cho, U.K. (2009). A novel evolutionary approach to image enhancement filter design: Method and applications. IEEE Transactions on Systems, Man, and Cybernetics, Part B (Cybernetics), 39(6): 1446-1457.

Hoon Lim, D. (2006). Robust rank-order test for edge detection in noisy images. Nonparametric Statistics, 18(3): 333342.

Huynh-Thu, Q., Ghanbari, M. (2008). Scope of validity of PSNR in image/video quality assessment. Electronics letters, 44(13): 800-801.

Jain, P., Tyagi, V. (2016). A survey of edge-preserving image denoising methods. Information Systems Frontiers, 18(1): 159-170.

Lim, D.H. (2006). Robust edge detection in noisy images. Computational Statistics \& Data Analysis, 50(3): 803-812.

Routray, S., Ray, A.K., Mishra, C. (2018). Image denoising by preserving geometric components based on weighted bilateral filter and curvelet transform. Optik, 159: 333-343.

Selesnick, I.W., Parekh, A., Bayram, I. (2014). Convex 1-D total variation denoising with non-convex regularization. IEEE Signal Processing Letters, 22(2): 141-144.

Shao, L., Yan, R., Li, X., Liu, Y. (2013). From heuristic optimization to dictionary learning: A review and comprehensive comparison of image denoising algorithms. IEEE transactions on cybernetics, 44(7): 1001-1013.

Shen, Y., Liu, Q., Lou, S., Hou, Y.L. (2017). Wavelet-based total variation and nonlocal similarity model for image denoising. IEEE Signal Processing Letters, 24(6): 877-881.

Singh, K., Ranade, S.K., Singh, C. (2017). Comparative performance analysis of various wavelet and nonlocal means based approaches for image denoising. Optik, 131: 423437.

Srivastava, A., Bhateja, V., Tiwari, H. (2015). Modified anisotropic diffusion filtering algorithm for MRI. In: $20152^{\text {nd }}$ International Conference on Computing for Sustainable Global Development (INDIACom), 1885-1890.

Starck, J.L., Candès, E.J., Donoho, D.L. (2002). The curvelet transform for image denoising. IEEE Transactions on image processing, 11(6): 670-684.

Tomasi, C., Manduchi, R. (1998). Bilateral filtering for gray and color images. In: $6^{\text {th }}$ International Conference on Computer Vision (IEEE Cat. No. 98CH36271), 839-846.

Ünver, H.M., Kökver, Y., Duman, E., Erdem, O.A. (2019). Statistical edge detection and circular hough transform for optic disk localization. Applied Sciences, 9(2), 350; DOI: 10.3390/app9020350

Verma, O.P., Hanmandlu, M., Susan, S., Kulkarni, M., Jain, P.K. (2011). A simple single seeded region growing algorithm for color image segmentation using adaptive thresholding. In: 2011 International Conference on Communication Systems and Network Technologies, 500-503.

Wang, L., Wei, L.Y., Zhou, K., Guo, B., Shum, H.Y. (2007). High Dynamic Range Image Hallucination. In: Rendering Techniques, 321-326. 
An Edge Preserving Image Denoising Framework Based on Statistical Edge Detection and Bilateral Filter

Wang, Z., Bovik, A.C., Sheikh, H.R., Simoncelli, E.P. (2004). Image quality assessment: from error visibility to structural similarity. IEEE Transactions on Image Processing, 13(4): 600-612.
Weickert, J. (1998). Anisotropic diffusion in image processing. Teubner Stuttgart.

Zhang, B., Allebach, J.P. (2008). Adaptive bilateral filter for sharpness enhancement and noise removal. IEEE Transactions on Image Processing, 17(5): 664-678. 